\title{
Correlation of periodontal pathogens in concurrent endodontic-periodontal diseases
}

Amela Lačević ${ }^{*}$, Federico Foschii ${ }^{2,3}$, Lejla Pojskić ${ }^{4}$, Naris Pojskić ${ }^{4}$, Kasim Bajrović ${ }^{4}$ and Jacques Izard ${ }^{5,6}$

Corresponding: amelalacevic@yahoo.com

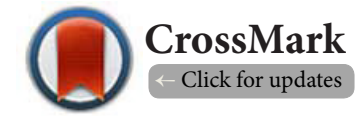

'Department of Dental Pathology and Endodontic, School of Dentistry, University of Sarajevo, Bolnička 4a, 71000 Sarajevo, Bosnia and Herzegovina.

${ }^{2}$ Department of Restorative Dentistry, King's College London Dental Institute at Guy's, UK.

${ }^{3}$ St Thomas' Hospital, Floor 25, Tower Wing, Guy's Hospital, St Thomas' St, London SE1 9RT, UK.

${ }^{4}$ Institute for Genetic Engineering and Biotechnology, University of Sarajevo, Zmaja od Bosne 8, Kampus, 71000 Sarajevo, Bosnia and Herzegovina.

${ }^{5}$ The Forsyth Institute, 245 First Street, Cambridge MA 02142, USA.

${ }^{6}$ Harvard School of Dental Medicine, 188 Longwood Avenue, Boston MA, 02115, USA.

\begin{abstract}
Objectives: This study investigated the correlation between Tannerella forsythia, Porphyromonas gingivalis, Fusobacterium nucleatum, and Aggregatibacter actinomycetemcomitans at dual sites in concurrent endodonticperiodontal diseases.

Material and methods: Samples were collected from endodontium and periodontium in cases of concurrent endodontic-periodontal diseases from thirty participants. The sensitivity and specificity of SYBR Green real-time PCR was used to identify the targeted species. Absolute number of targeted genome copies in tested samples were extrapolated from respective calibration curve.

Results: No statistical difference was found in the number of detected endodontic-periodontal pathogens between the endodontium and periodontium. The Pearson test detected significant correlation $(\mathrm{P}<0.001)$ between targeted bacteria; T. forsythia, F. nucleatum, and P. gingivalis from endodontic-periodontal lesions. Synergistic component observed separately in endodontic biofilm was found only between T. forsythia and F. nucleatum $(\mathrm{r}=0.380, \mathrm{P}=0.03$ ) while in periodontal biofilm $T$. forsythia, $F$. nucleatum and $P$. gingivalis gave high synergism result $(\mathrm{P}<0.0001)$. Correlation analysis showed that $T$. forsythia in primary endodontic infection and in periodontal lesion was significantly decreased with the increase of patients age $(\mathrm{r}=-0.308$, $\mathrm{P}=0.017)$.

Conclusions: Correlation between targeted bacterial species levels from concurrent endodonticperiodontal diseases confirmed that coronal and cervical dentinal tubules may represent a viable pathway that allows spreading and maintaining of dual sites infection. Periodontal bacteria detected in root canal of concurrent endodontic-periodontal infections may originate from the local periodontal lesions.
\end{abstract}

Keywords: Microbiome correlation, dentinal tubules, endo-perio infection, pearson test, periodontal lesion

\section{Introduction}

The route of infection within endodontic-periodontal niche is still a subject of unresolved controversy as it is unclear if the bacterial migration occurs through dentinal tubules. The openings of dentinal tubules facing the periodontal ligament are sealed with cementum. Dentinal cementum can be mechanically removed, abraded, eroded, and destroyed by clinical, pathologi$\mathrm{cal}$ and erosive processes. Until recently the gold standard in periodontal treatment would have been scaling and root planning, where the removal of infected cementum was considered a condicio sine qua non. Bacteria of the oral biofilm adhering on the root surface can obtain access to the adjacent dentinal 
tubules [1]. Anatomical communications such as: apical foramen, accessory canals, lateral canals and dentinal tubules link the two endodontic-periodontal niches [2-4]. While cementum may represent a barrier for bacterial migration through dentinal tubules, movement of bacteria from the outer surface of the root to the root canal system may reinforce the reservoir effect of the dentinal tubules. The different depths of penetration maybe related to the bacterial size, adhesive properties, and motility characteristics [5]. The degree of permeability varies between different areas of the tooth and the age of the patient $[5,6]$. In model systems it is shown that persistence in small space is mostly related to availability of nutrient in the context of spatial constriction that might be stricter than cell dimensions [7].

According to Harrington et al., [8] dental pulp is capable of surviving significant insults, unless periodontal disease extends all the way to the tooth apex, so the effect of periodontal disease and periodontal treatment on dental pulp is expected to be negligible. Conversely in other publications, it was suggested that periodontal disease is a direct cause of pulpal atrophy and necrosis, and periodontal diseases should be regarded as potential causes of pulpitis and pulpal necrosis [9-12].

The connection between the endodontic and periodontal niches in terms of pathogens involved has been investigated by traditional and molecular methods $[13,14]$. Considering the fact that the vital pulp tissue can immunologically respond to bacteria and bacterial bioproducts and preserve its vitality, the type of infection investigated in this study was primary endodontic infection with chronic periodontitis [15]. Our working hypothesis was that bacteria may migrate through dentinal tubules in both directions colonizing both endodontic-periodontal tissues, as supported by previous investigation [9,16-18].

The aim of this study was to explore quantitative distribution of periodontal pathogens between endodontic and periodontal samples of the same tooth. In that respect we have analyzed the occurrence of key periodontal pathogens such as: Tannerella forsythia, Porphyromonas gingivalis, Fusobacterium nucleatum, Aggregatibacter actinomycetemcomitans using SYBR Green based real-time PCR assay. Furthermore, we assessed bacterial interrelations in clinically validated cases of endodontic-periodontal infections using statistical correlation tests. The null hypothesis of the study was that no correlation existed between the pathogens sampled in periodontal and endodontic lesions.

\section{Materials and methods Subject recruitment}

Study's participants were screened patients of the Department of Dental Pathology and Endodontics, School of Dentistry, University of Sarajevo. Thirty patients fulfilled enrollment criteria. Inclusion criteria included: age between 18-60 years, primary endodontic infection of single rooted tooth diagnosed as chronic apical periodontitis or acute apical periodontitis or localised absceses and concomitant periodontal lesions with chronic periodontitis. Periodontal pockets were not deeper than $6 \mathrm{~mm}$. Endodontic-periodontal lesions were diagnosed clinically and by long-cone periapical radiograph. Exclusion criteria were the use of antibiotic in the previous two months, the presence of fistula, radiographic evidence of endodontic-periodontal communication, and aggressive form of periodontitis. Clinical metadata and measurements were collected at the time of collection. All participants in this study were recruited on the basis of informed consent and procedures were done with respect to local ethical standards in accordance with Helsinki Declaration.

\section{Specimen sampling}

Periodontal samples were taken following supragingival biofilm removal and cotton roll isolation by inserting two paper points (ISO 20) into the deepest periodontal pockets and left in situ for 1 minute each. Samples from the root canal of the diagnosed tooth were collected under rubber-dam isolation and under strict aseptic conditions. Samples were collected from single root during endodontic treatment. The tooth and the surrounding field were cleansed with $3 \%$ hydrogen peroxide and decontaminated with a $2.5 \%$ sodium hypochlorite solution. Complete access preparations were made using sterile burs without irrigation, and the operative field including the pulp chamber, was then swabbed with $2.5 \% \mathrm{NaOCl}$, which was then inactivated by sterile $5 \%$ sodium thiosulphate. Samples were collected using a size $20 \mathrm{~K}$-type file, held with sterile locking pliers, and introduced to a level approximately $1 \mathrm{~mm}$ short of the tooth apex, based on diagnostic radiographs. Two sequential sterile paper points (ISO 20) were placed to the working length level and used to soak up the fluid in the root canal. Each paper point was left in position for 1 minute. The file and the two paper points were then transferred to cryotubes containing $1 \mathrm{ml}$ of TE buffer (10 $\mathrm{mmol} / \mathrm{l}$ tris- $\mathrm{HCl}, 0.1 \mathrm{mmol} / \mathrm{l} \mathrm{EDTA}, \mathrm{pH}$ 7.6). Samples were immediately frozen and kept at $-80^{\circ} \mathrm{C}$ prior to further analysis.

\section{DNA extraction}

Before the DNA extraction, frozen endodontic and periodontal specimens were resuspended and thawed at room temperature. Total DNA from endodontic and periodontal samples was extracted using Qiamp DNA (Qiagen, Hilden, Germany) mini kit according to manufacturer's instructions. DNA concentration and purity were evaluated using UV mini spectrophotometer 1240 (Shimadzu, Japan).

\section{Primers description and amplification}

Detection of all targeted periodontal pathogens was performed using PCR with previously published strain specific primers pairs listed below: for T. forsythia, Tf forward 5'-GCG TAT GTA ACC TGC CCG CA-3' Tf reverse 5'-TGC TTC AGT GTC AGT TAT ACC T-3' with amplicon length 641 base pairs [19]; for F. nucleatum Fn forward 5'-AGA GTT TGA TCC TGG CTC AG-3' Fn reverse 5'-GTC CTC GTG CAC ACA GAA TTG CTG -3' with amplicon length $360 \mathrm{bp}$ [20]; P. gingivalis $P g$ forward $5^{\prime}$ AGG CAG CTT GCC ATA CTG CG-3' $P g$ reverse 5'-ACT GTT AGC AAC TAC CGA TGT-3' with amplicon length 404 bp [21]; and for A. actinomycetemcomitans [1], Aa forward 5'-AAA CCC 
Lačević et al, Oral Biology and Dentistry 2015,

http://www.hoajonline.com/journals/pdf/2053-5775-3-5.pdf

ATC TCT GAG TTC TTC TTC AG-3' Aa reverse 5'-ATG CCA ACT TGA CGT TAA AT-3' with amplicon length 557 bp [22].

Amplification reaction mixture for temperature gradient optimization contained $200 \mathrm{ng}$ of DNA template, $2.5 \mu \mathrm{PCR}$ buffer, $2 \mathrm{mmol} \mathrm{MgCl}_{2}, 0.5 \mu \mathrm{mol} / \mathrm{l} \mathrm{dNTP}, 1 \mathrm{pmol}$ of each primer, 0.25 units of Taq DNA polymerase, $16.6 \mu \mathrm{dddH}_{2} \mathrm{O}$ and $0.25 \mu \mathrm{l}$ of glycerol in a total volume of $25 \mu$. The PCR program with temperature profile for all primers included an initial denaturation step at $90^{\circ} \mathrm{C}$ for $3 \mathrm{~min}$, followed by 35 cycles of a denaturation step at $95^{\circ} \mathrm{C}$ for $30 \mathrm{~s}$, then 35 cycles annealing step at $55-65^{\circ} \mathrm{C}$ for $1 \mathrm{~min}$, and 35 cycles of elongation step at $72^{\circ} \mathrm{C}$ for $1 \mathrm{~min} 30$ $\mathrm{s}$, and final elongation at $72^{\circ} \mathrm{C}$ for $5 \mathrm{~min}$.

The purpose of temperature gradient optimization was to achieve proper individual temperature for primers amplification, before SYBR Green Real-Time PCR program was carried out. Adequate temperature profile for primers annealing was necessary preconditioning for the SYBR Green Real-Time PCR program to achieve appropriate quantitation results.

\section{SYBR Green real-time PCR}

Real Time PCR reactions were carried out in total volume of $12 \mu \mathrm{l}$ containing PCR SYBR Green premix (SYBR Green I dye, Ampli Taq DNA polymerase, dNTP with dUTP, passive reference dye and optimized buffer component) in a volume 6.25 $\mu \mathrm{l}$, each primer $20 \mathrm{pmol}, 200 \mathrm{ng}$ of DNA template and sterile distilled water to adjust the total volume of $12 \mu \mathrm{l}$.

Amplification and detection of bacterial DNA by SYBR Green was performed in a 7300 Real-Time PCR System (Applied Biosystems Foster City USA) with the programs for cycling conditions which started with initial denaturation step at $95^{\circ} \mathrm{C}$ for $3 \mathrm{~min}$, followed by 35 cycles of denaturation step at $95^{\circ} \mathrm{C}$ for $45 \mathrm{~s}$, then 35 cycles of annealing at $60^{\circ} \mathrm{C}$ for $1 \mathrm{~min}$ and 35 cycles of elongation step at $72^{\circ} \mathrm{C}$ for $1 \mathrm{~min} 30 \mathrm{~s}$ and finally 3 cycles of dissociation at $95^{\circ} \mathrm{C}$ for $15 \mathrm{~s}$, at $60^{\circ} \mathrm{C}$ for $30 \mathrm{~s}$, at $95^{\circ} \mathrm{C}$ for 15 s. All samples were run in duplicate. Amplification results of T. forsythia, P. gingivalis, F. nucleatum, and A. actinomicetem comitans were collected in form of $\mathrm{Ct}$ values or threshold cycle which is the intersection between an amplification curve and a threshold line to derive the concentration of the target in the reaction. Efficacy of SYBR Green Real Time PCR quantitation experiment was validated by dissociation curve analysis method.

\section{Absolute quantitation method}

In order to determine exact number of bacterial DNA copies for all investigated strains we used a calibration curve analysis based on serial dilutions of pure DNA extracts from $5 \times 10^{1}-5 \times 10^{6}$ genome copies. Strains were obtained from the American Type Culture Collection (ATCC; Manassas, VA): P. gingivalis ATCC 33277, A. actinomycetemcomitans ATCC 29523, F. nucleatum ATCC 25586, T. forsythia ATCC 43037. Absolute number of genome copies in tested samples was extrapolated from respective calibration curve.

\section{Biostatistical analysis}

Student- $\mathrm{T}$ test $(\mathrm{P}<0.05)$ was used to check the endodontic-peri- odontal microbial interrelationships for each respective sample. Analyses of variance (ANOVA) was implemented in order to detect possible bacterial influence on clinical symptoms and endodontic-periodontal diagnosis. Pearson correlation test was used to assess correlation in copy number of targeted bacterial strains in the concurrent endodontic-periodontal lesion. The same test was used to estimate correlation between absolute quantitation of targeted bacteria separately in endodontic and periodontal biofilm. Also, correlation test was implemented to perceive possible association between copy number of targeted bacterial strains and patient's age. The SPSS 10 software (SPSS Inc.; Chicago, IL) was used for statistical analysis.

\section{Results}

Thirty subjects (age $37 \pm 13.74 ; 57 \%$ females and $43 \%$ males) fulfilled recruitment criteria. In total sixty specimens were sampled from endodontium and periodontium. The most frequently detected species was F. nucleatum (100\% of both endodontic and periodontal samples), followed by T. forsythia (93\% of periodontal pocket samples; $90 \%$ in primary endodontic infection), P. gingivalis (53\% of periodontal pocket samples; $70 \%$ in primary endodontic infection), and A. actinomycetemcomitans (13\% of periodontal pocket samples; $3 \%$ in primary endodontic infection). There was no statistically significant difference in the quantity of targeted pathogens between the endodontium and periodontium of the same tooth as found by T-test (Table 1). As A. actinomycetemcomitans was detected in both endodontic and periodontal samples with a low representation among the participants as well as at low levels, this bacteria was excluded from further analyses.

Pearson correlation test detected association between targeted bacteria from endodontic-periodontal lesions and co-localization among detected bacteria from endodontium and periodontium separately. Analysis between bacteria in endodontic-periodontal infection confirmed statistically significant correlation between absolute quantitation of $T$. forsythia and F. nucleatum ( $\mathrm{r}=0.547$, $\mathrm{P}<0.0001)$, F. nucleatum and $P$. gingivalis $(\mathrm{r}=0.427, \mathrm{P}<0.01)$, while $T$. forsythia and $P$. gingivalis showed tendency toward statistical correlation in endodontic-periodontal infections $(\mathrm{r}=0.244, \mathrm{P}=0.06)$. Pearson test showed statisticaly significant correlation between T. forsythia and F. nucleatum $(\mathrm{r}=0.682$, $\mathrm{P}<0.0001)$, F. nucleatum and $P$. gingivalis $(\mathrm{r}=0.977, \mathrm{P}<0.0001)$,

Table 1. Comparsion of bacterial quantity by T-test from endodontium and periodontium of the same tooth using absolute quantitation real time PCR method.

\begin{tabular}{llll}
\hline & P & $\begin{array}{l}\text { Average } \\
\text { difference in } \\
\text { copy number }\end{array}$ & Std.error \\
\hline T. forsythia & 0.571 & -5584.1 & 9801.4487 \\
F. nucleatum & 0.319 & -49241287319 & 48991947514 \\
P. gingivalis & 0.724 & 216373.8 & 610683.46 \\
A. actinomicetemcomitans & 0.324 & -174.59 & 175.57 \\
\hline
\end{tabular}


Lačević et al, Oral Biology and Dentistry 2015,

as well as T. forsythia and P. gingivalis $(\mathrm{r}=0.691, \mathrm{P}<0.0001)$ indicating a potential sinergistic component in periodontal biofilm. Significant correlation between targeted bacteria from endodontic biofilm was only observed between $T$. forsythia and F. nucleatum ( $\mathrm{r}=0.380, \mathrm{P}=0.03)$.

Correlation analysis showed that only T. forsythia in primary endodontic infection and in periodontal lesion was significantly decreased with the increase of patients age $(r=-0.308, P=0.017)$. Only F. nucleatum in endodontic-periodontal lesions showed statistically significant difference in cases of acute apical periodontitis and clinical features such as localised abscesses $(\mathrm{F}=3.586, \mathrm{P}>0.05)$.

\section{Discussion}

SYBR Green real-time PCR was used in this study for its high level of detection sensitivity and specificity. Potential PCR inhibitors in our reaction mixture were either absent or present in amounts not sufficient to significantly interfere with the reaction. The high frequency of the targeted bacteria in this study is a result of the SYBR Green real-time PCR detection method high sensitivity, and confirms previous results [23,24]. Positive statistical correlation of absolute quantitation of the targeted species and the increase of pocket depth was not observed, possibly due to the measuring depth not deeper than $6 \mathrm{~mm}$. The purpose of this limitation was to facilitate the demonstration that the coronal and middle part of the root is frequently used bacterial pathway in both, endodontic and periodontal direction. Differences in size, number and diameter of dentinal tubules depend on the area of the root. Progressive and pathological sclerosis and obliteration of dentinal tubules affect the size of dentinal tubules diameter [6]. Cervical and mid-root dentin has a higher tubular density while the apical region is consisted of lower number of dentinal tubules with sclerosis and obliteration tendency [25].

In periodontal pockets, T. forsythia, F. nucleatum and $P$. gingivalis high statistical correlations of their quantitation, as found by Pearson test, suggest optimal environmental conditions for bacterial growth in periodontal pocket. In contrast, the same strains from the root canal of same tooth resulted in statistically less significant correlation. Those findings underline the environmental influence on bacterial growth, as the root canal condition may be less favorable than the periodontal niche for a synergistic interaction among those organisms. Environmental influence and conditions can lead to nonspecific microbial presence in the root canal, and is one of the reasons why endodontic specialists do not have root canal filling for all endodontic infections [26]. The environmental effect as a direct consequence for the subjects as the observed periapical and periradicular radiolucencies associated event promote development of marginal bone loss and consequently should be regarded as a risk factor in periodontitis progression [8]. For clinicians this means that in their treatment protocol they always need to first complete endodontic treatment and then terminate periodontal treatment [26].
T. forsythia in primary endodontic infection and in periodontal lesion showed significant decrease in correlation with the increase of patients age. The detection of T. forsythia both in primary endodontic infection and periodontal lesion is in accordance with previous investigation using non targeted molecular methods [27]. F. nucleatum levels in endodonticperiodontal lesions correlated with symptoms of severe pain in cases of acute apical periodontitis and localized abscesses.

The low prevalence of $A$. actinomycetemcomitans in the primary endodontic infection is in agreement with previous research [28], and may be associated in our study with the exclusion of aggressive form of periodontitis and an average periodontal pocket depth of $4 \mathrm{~mm}$, and no deeper than $6 \mathrm{~mm}$. A. actinomycetemcomitans, found in this study, is not a relevant endodontic pathogen and the environmental differences between the root canal and periodontal pocket probably determined the low prevalence of this bacteria in the root canal system.

T. forsythia, $P$. gingivalis, and F. nucleatum detected in this study were positively associated with endodontic-periodontal combined infection. F. nucleatum in endodontic-periodontal lesions correlation with the symptoms of severe pain in cases of acute apical periodontitis as well as clinical features such as localised abscesses echoe the findings of Villanueva [29].

The number of detected bacterial copies between endodontium and periodontium space had no significant difference, confirming the working hypothesis. Endodontic infections are sustaining periodontal lesions and periodontal lesions are most likely a bacterial source for endodontic infections [13]. Correlation between targeted bacterial species from concurrent endodonticperiodontal diseases confirmed that coronal and cervical dentinal tubules may represent a viable pathway that allows spreading and maintaining of dual sites infection. Periodontal bacteria detected in root canal of concurrent endodontic-periodontal infections may originate from the local periodontal lesions.

The limitations of the study are associated with the targeted nature of the approach and the number of participants. The targeted nature of this approach limits to known species that have been associated with dysbiosis in and around the tooth structure. Future studies should include untargeted approaches such as targeted gene sequencing using next-generation sequencing $[30,31]$, which has yet to be applied to this topic. The number of participant while limited to thirty individuals allowed an in depth analysis of two adjacent sites from the same tooth, limiting the scale of recruitment. Future studies could include the microbiota of adjacent teeth to validate the findings.

\section{Conclusions}

In this study, we investigated the controversial issue related to clinical questions whether bacteria from periodontium could migrate through coronal and middle part of the root dentinal tubules and infect the pulp tissue and vice-versa Absolute quantitation of the frequent periodontal and endodontic pathogens using SYBR Green real-time PCR confirmed working hypothesis and reveled no statistically significant difference in the presence 
of the targeted bacteria in endodontic-periodontal infections. Molecular detection method facilitated the demonstration of the coronal and middle part of the root as frequently used bacterial pathway in both, endodontic and periodontal direction.

This research emphasized that endodontic bacteria most likely originate from periodontal pockets and that endodontic infections maintain periodontal pockets and periodontal infection.

\section{Competing interests}

The authors declare that they have no competing interests.

\section{Author's contributions}

All authors contributed equally to the manuscript.

\section{Acknowledgement}

The study was funded in part by NIH CA166150 (JI).

Publication history

Received: 30 July 2015 Revised: 01 September 2015

Accepted: 11 September 2015 Published: 22 September 2015

\section{References}

1. Zehnder, M., Gold, S. I. and Hasselgren, G. (2002). Pathologic interactions in pulpal and periodontal tissues. J Clin Periodontol, 29, 663-71.

2. Vertucci, F. J. and Anthony, R. L. (1986). A scanning electron microscopic investigation of accessory foramina in the furcation and pulp chamber floor of molar teeth. Oral Surg Oral Med Oral Pathol, 62, 319-26.

3. Perlich, M.A., Reader, A. and Foreman, D.W. (1981). A scanning electron microscopic Checkerboard DNA-DNA hybridization analysis of endodontic infections. Oral Surg, Oral Med, Oral Pathol, 89, 744-748.

4. Langeland, K., Rodrigues, H. and Dowden, W. (1974). Periodontal disease, bacteria, and pulpal histopathology. Oral Surg Oral Med Oral Pathol, 37, 257-70.

5. Kakoli, P., Nandakumar, R., Romberg, E., Arola, D. and Fouad, A. F. (2009). The effect of age on bacterial penetration of radicular dentin. J Endod, 35, 78-81.

6. Love, R.M. (2002). Invasion of dentinal tubules by oral bacteria. Crit Rev in Oral Biol Med, 13, 171-183.

7. Mannik, J., et al. (2009). "Bacterial growth and motility in submicron constrictions." Proc Natl Acad Sci U S A, 106, 1486114866.

8. Harrington, G.W. and Steiner, D.R. (2002). Periodontalendodontic considerations. In: Walton, R.E., Torabinejad, M. Principles and Practice of Endodontics $3^{\text {rd }}$ edition Philadelphia, 466-484.

9. Jansson, L., Ehnevid, H., Lindskog, S. and Blomlof, L. (1993). Relationship between periapical and periodontal status. A clinical retrospective study. J Clin Periodontol, 20, 117-123.

10.Ehnevid, H., Jansson, L., Lindskog, S. and Blomlof, L. (1993). Periodontal healing in teeth with periapical lesions. A clinical retrospective study. J Clin Periodontol, 20, 254-8.

11.Wang, H.L. and Glickman, G.N. (2002). Endodontic and periodontic inerrelationships. In: Cohen, S., Burns, R.C. Pathways of the Pulp $8^{\text {th }}$ edition, 651-66.
12.Petka, K. (2001). The 14 warning signs. Endod Practic, 4, 18-26.

13. Fuji, R., et al. (2014). "An endodontic-periodontal lesion with primary periodontal disease: a case report on its bacterial profile." Bull Tokyo Dent Coll, 55, 33-37.

14. Kurihara, H., Kobayashi, Y., Francisco, I. A., Isoshima, O., Nagai, A. and Murayama, Y. (1995). A microbiological and immunological study of endodontic-periodontic lesions. J Endod, $21,617-21$

15.Bender, I.B. and Seltzer, S. (1972). The effect of periodontal disease on the pulp. Oral Surg, 33, 458-474.

16. Rupf, S., Kannengießer, S., Merte, K., Pfister, W., Sigusch, B. and Eschrich, S. (2000). Comparison of profiles of key periodontal pathogens in periodontium and endodontium. Endod Dent Traum, 16, 269-275.

17.Jansson, L., Ehnevid, H., Blomlof, L., Weintraub, A. and Lindskog, S. (1995). Endodontic pathogens in periodontal disease augmentation. J Clin Periodontol, 22, 598-602.

18. Chen, S.Y., Wang, H.L. and Glickman, G.N. (1997). The influence of endodontic treatment upon periodontal wound healing. J Clin Periodontol, 24, 449-456.

19. Ashimoto, A., Chen, C., Bakker, I. and Slots, J. (1996). Polymerase chain reaction detection of 8 putative periodontal pathogens in subgingival oral biofilm of gingivitis and advanced periodontitis lesions. Oral Microbiol Immunol, 11, 266-73.

20.Conrads, G., Gharbia, S.E., Gulabivala, K., Lampert, F. and Shah, H.N. (1997). The use of a $16 \mathrm{~S}$ rDNA directed PCR for the detection of endodontopathogenic bacteria. J Endod, 23, 433-438.

21. Mättö, J., Saarela, M., Alaluusua, S., Oja, V., Jousimies-Somer, H. and Asikainen, S.(1998). Detection of Porphyromonas gingivalis from saliva by PCR by using a simple sample-processing method. J Clin Microb, 36, 157-160.

22. Furcht, C., Eschrich, K. and Merte, K. (1996). Detection of Eikenella corrodens and Actinobacillus actinomycetemcomitans by use of the polymerase chain reaction (PCR) in vitro and in subgingival plaque. J Clin Periodontol, 23, 891-7.

23. Kawada, M., Yoshida, A., Suzuki, N., Nakano, Y., Saito, T., Oho, T. and Koga, T. (2004). Prevalence of Porphyromonas gingivalis in relation to periodontal status assessed by real-time PCR. Oral Microbiol Immunol, 19, 289-92.

24. Gomes, B. P., Montagner, F., Jacinto, R. C., Zaia, A. A., Ferraz, C. C. and Souza-Filho, F. J. (2007). Polymerase chain reaction of Porphyromonas gingivalis, Treponema denticola, and Tannerella forsythia in primary endodontic infections. J Endod, 33, 1049-52.

25. Kakoli, P., Nandakumar, R., Romberg, E., Arola, D. and Fouad, A. F. (2009). The effect of age on bacterial penetration of radicular dentin. J Endod, 35, 78-81.

26. Abbot, P.V. and Salgado, J.C. (2009). Strategis for the endodontic managment of concurrent endodontic and periodontal diseases. Austral Dent J, 54, 570-585.

27.Socransky, S.S. and Haffajee, A.D. (2002). Dental biofilms: difficult therapeutic targets. Periodontol, 28, 12-55.

28. Siqueira, J. F., Jr. (2003). Taxonomic changes of bacteria associated with endodontic infections. J Endod, 29, 619-23.

29. Villanueva, L.E.C.P. (2002). Fusobacterium nucleatum in endodontic flare-ups. Oral Surg, Oral Med, Oral Pathol, Oral Radiol Endod, 93, 179-183.

30. Segata, N., et al. (2012). "Composition of the adult digestive tract 
Lačević et al, Oral Biology and Dentistry 2015,

http://www.hoajonline.com/journals/pdf/2053-5775-3-5.pdf

bacterial microbiome based on seven mouth surfaces, tonsils, throat and stool samples." Genome Biol, 13, R42.

31. Anderson AC, Al-Ahmad A, Elamin F, Jonas D and Mirghani Y, et al. (2013). Comparison of the Bacterial Composition and Structure in Symptomatic and Asymptomatic Endodontic Infections Associated with Root-Filled Teeth Using

Pyrosequencing. PLoS ONE, 8, e84960.

\section{Citation:}

Lačević A, Foschi F, Pojskić L, Pojskić N, Bajrović K and Izard J. Correlation of periodontal pathogens in concurrent endodontic-periodontal diseases. Oral Biol Dent. 2015; 3:5.

http://dx.doi.org/10.7243/2053-5775-3-5 